\title{
Maternal mortality in six low and lower- middle income countries from 2010 to 2018: risk factors and trends
}

Melissa Bauserman ${ }^{1 *}$ (D, Vanessa R. Thorsten², Tracy L. Nolen², Jackie Patterson ${ }^{1}$, Adrien Lokangaka $^{3}$, Antoinette Tshefu ${ }^{3}$, Archana B. Patel ${ }^{4,5}$, Patricia L. Hibberd ${ }^{6}$, Ana L. Garces ${ }^{7}$, Lester Figueroa ${ }^{7}$, Nancy F. Krebs ${ }^{8}$, Fabian Esamai ${ }^{9}$, Paul Nyongesa ${ }^{9}$, Edward A. Liechty ${ }^{10}$, Waldemar A. Carlo ${ }^{11}$, Elwyn Chomba ${ }^{12}$, Shivaprasad S. Goudar ${ }^{13}$, Avinash Kavi ${ }^{13}$, Richard J. Derman ${ }^{14}$, Sarah Saleem ${ }^{15}$, Saleem Jessani ${ }^{15}$, Sk Masum Billah ${ }^{16,17}$, Marion Koso-Thomas ${ }^{18}$, Elizabeth M. McClure ${ }^{2}$, Robert L. Goldenberg ${ }^{19}$ and Carl Bose ${ }^{1}$

From Global Network

Virtual. 3-15 Septemeber 2020

\begin{abstract}
Background: Maternal mortality is a public health problem that disproportionately affects low and lower-middle income countries (LMICS). Appropriate data sources are lacking to effectively track maternal mortality and monitor changes in this health indicator over time.

Methods: We analyzed data from women enrolled in the NICHD Global Network for Women's and Children's Health Research Maternal Newborn Health Registry (MNHR) from 2010 through 2018. Women delivering within research sites in the Democratic Republic of Congo, Guatemala, India (Nagpur and Belagavi), Kenya, Pakistan, and Zambia are included. We evaluated maternal and delivery characteristics using log-binomial models and multivariable models to obtain relative risk estimates for mortality. We used running averages to track maternal mortality ratio (MMR, maternal deaths per 100,000 live births) over time.
\end{abstract}

Results: We evaluated 571,321 pregnancies and 842 maternal deaths. We observed an MMR of 157 / 100,000 live births $(95 \% \mathrm{Cl} 147,167)$ across all sites, with a range of MMRs from $97(76,118)$ in the Guatemala site to $327(293,361)$ in the Pakistan site. When adjusted for maternal risk factors, risks of maternal mortality were higher with maternal age > 35 (RR $1.43(1.06,1.92)$ ), no maternal education (RR $3.40(2.08,5.55)$ ), lower education (RR $2.46(1.54,3.94))$, nulliparity (RR $1.24(1.01,1.52)$ ) and parity $>2$ (RR $1.48(1.15,1.89))$. Increased risk of maternal mortality was also associated with occurrence of obstructed labor (RR $1.58(1.14,2.19)$ ), severe antepartum hemorrhage (RR $2.59(1.83,3.66))$ and hypertensive disorders (RR $6.87(5.05,9.34)$ ). Before and after adjusting for other characteristics, physician attendance at delivery, delivery in hospital and Caesarean delivery were associated with increased risk. We observed variable changes over time in the MMR within sites.

(Continued on next page)

\footnotetext{
* Correspondence: melissa_bauserman@med.unc.edu

${ }^{1}$ Department of Pediatrics, University of North Carolina School of Medicine,

101 Manning Drive, CB 7596, Chapel Hill, NC 27599-7596, USA

Full list of author information is available at the end of the article
}

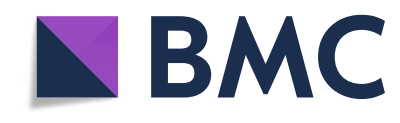

(c) The Author(s). 2020 Open Access This article is licensed under a Creative Commons Attribution 4.0 International License, which permits use, sharing, adaptation, distribution and reproduction in any medium or format, as long as you give appropriate credit to the original author(s) and the source, provide a link to the Creative Commons licence, and indicate if changes were made. The images or other third party material in this article are included in the article's Creative Commons licence, unless indicated otherwise in a credit line to the material. If material is not included in the article's Creative Commons licence and your intended use is not permitted by statutory regulation or exceeds the permitted use, you will need to obtain permission directly from the copyright holder. To view a copy of this licence, visit http://creativecommons.org/licenses/by/4.0/ The Creative Commons Public Domain Dedication waiver (http://creativecommons.org/publicdomain/zero/1.0/) applies to the data made available in this article, unless otherwise stated in a credit line to the data. 
(Continued from previous page)

Conclusions: The MNHR is a useful tool for tracking MMRs in these LMICs. We identified maternal and delivery characteristics associated with increased risk of death, some might be confounded by indication. Despite declines in MMR in some sites, all sites had an MMR higher than the Sustainable Development Goals target of below 70 per 100,000 live births by 2030 .

Trial registration: The MNHR is registered at NCT01073475.

Keywords: Low-resource countries, Maternal mortality, Sustainable development goals, Global network

\section{Plain English summary}

Reducing maternal mortality is a global health priority. Maternal mortality disproportionately affects women in low and lower-middle income countries, and many of these deaths are preventable. We describe maternal death in research sites in the Democratic Republic of Congo, Guatemala, India (Nagpur and Belagavi), Kenya, Pakistan, and Zambia. We emphasize that the number of women dying in these countries is higher than the targets set out in the World Health Organization's Sustainable Development Goals for 2030. We describe large differences between countries in terms of the ratio of maternal death. We identify maternal and delivery characteristics associated with increased risk of death, although some of the characteristics might be influenced by other factors.

\section{Background}

Reducing maternal mortality is a global health priority. The Sustainable Development Goals (SDGs) aim for a reduction of the maternal mortality ratio (MMR) to below 70 per 100,000 live births by 2030 [1]. If the SDGs are met by 2030, the lives of an estimated 1.6 million mothers will be saved [2]. Maternal mortality is not only a health indicator, but also a key indicator of country development because maternal deaths have an important social and economic impact [3-5]. Maternal mortality disproportionately affects women in low and lower-middle income countries (LMICs) where most of the maternal deaths are from preventable causes [6].

Despite the majority of maternal deaths occurring in LMICs (MMR of 479 for low income countries compared to 41 in high income countries), robust systems for data collection and health indicator tracking are lacking [7]. This makes reliable tracking of MMRs difficult, despite global attention to the problem [8]. Also, controversy still exists regarding the optimal way to monitor maternal mortality [9]. In areas where health registries are lacking, the MMR can be estimated through a series of modelling strategies which rely on local data sources $[8,10,11]$. When data are sparse, such as in LMICs, these strategies rely on complex models with several poorly defined variables and weakly justified assumptions that lead to low precision in the final results $[10,12]$. Therefore, primary datasets that reliably track the MMR in LMICs are urgently needed to provide a more robust evidence base for evaluating and tracking maternal mortality [13].

In this manuscript, we describe maternal mortality in 6 LMICs from a defined geographic, community-based, prospectively collected maternal health registry that captures data on all women delivering within or outside of facilities. This longitudinal dataset describes maternal deaths over a 9-year period. We examine maternal characteristics associated with maternal deaths, causes of maternal death and evaluate site specific trends in the MMR over time.

\section{Methods}

We analyzed data from the Eunice Kennedy Shriver National Institute of Child Health and Human Development (NICHD) Global Network (GN) for Women's and Children's Health Research Maternal Newborn Health Registry (MNHR) [14]. The MNHR is a multicountry pregnancy registry including research sites in the Democratic Republic of Congo (DRC; North and South Ubangi Provinces); Guatemala (Western Highlands); India (Belagavi and Nagpur); Kenya (Western region); Pakistan (near the city of Karachi); and Zambia (south and east of the capital city of Lusaka). The study population includes both peri-urban and rural settings.

We included all pregnancies from January 2010 to December 2018, expanding on previously published results from 2010 to 2013 [15]. MNHR data, were collected from pregnant women who reside in or deliver within study clusters through various methods, including detailed interviews conducted by trained study staff, as well as abstraction from medical records. Women were identified for inclusion as early as possible during their pregnancy, then screened and consented. We collected baseline maternal characteristics at the time of entry into the registry. Additional antenatal and delivery characteristics were recorded within 3-7 days of delivery and postpartum details 
were collected at home or clinic visits 6 weeks after delivery. We excluded women who were lost to follow -up prior to delivery or those with missing data on maternal status at 42 days after the end of the pregnancy.

We defined maternal death in accordance with the World Health Organization definition of death of the mother while pregnant or within 42 days of the end of the pregnancy. We defined MMR as maternal deaths/100,000 live births. To calculate the MMR, we included all maternal deaths, regardless of the birth outcome (miscarriage, stillbirth, medical termination of pregnancy [MTP], live birth and unknown birth outcomes) in the numerator. The denominator is live born infants. The 95\% confidence interval for the MMR is approximated using the variance of the proportion of maternal deaths for each site and year. We defined fetal malposition as transverse lie, oblique lie or breech presentation.

We explored the relationship between characteristics and overall mortality using log-binomial generalized linear models with generalized estimating equations to obtain point and interval estimates of risk ratios for mortality modeled as a function of each characteristic independently while controlling for the correlation within clusters. For the purpose of the models, we evaluated the outcome of maternal death vs. women who survived to 42 days after the end of pregnancy. We included women who experienced all birth outcomes (miscarriage, stillbirth, live birth and unknown birth outcomes) in the models. Women without the characteristic (e.g. labor not obstructed) served as the reference group.

Next, we ran a multivariable regression model to determine the maternal, pregnancy related, delivery and antepartum factors that were associated with maternal death. Medical and social variables collected at the time of enrollment or around the time of delivery that could be associated with maternal mortality and were reliably collected in the MNHR were included. We included: maternal age, maternal education, parity, antenatal care (ANC), birth attendant, delivery mode, obstructed labor, fetal malposition, hemorrhage and hypertensive disorders. We defined severe antepartum hemorrhage as blood loss greater than $1000 \mathrm{~cm}^{3}$ (cc) of blood prior to delivery. Factors with significant missing fields were excluded. We adjusted the model further for research site and accounted for correlation of outcomes within clusters. Data are presented as adjusted risk ratios and 95\% confidence intervals. In 2013, the MNHR began assigning cause of maternal deaths by collecting data describing factors associated with deaths. We assigned a cause of death from these data using a standardized, hierarchical, algorithm [16].
The MNHR had some notable differences in its population over time. The DRC site entered the MNHR in 2014. Throughout the 9-year study period, there was expansion and contraction of clusters within each country to meet the research needs of the GN. In order to limit external forces that might alter the study population by inclusion of different clusters, we described the MMR over time using a subset of data. This subset included only GN clusters that were consistent throughout the 9-year period in the Guatemala, India (Nagpur and Belagavi), Kenya, Pakistan, and Zambia sites. For the DRC site, we included women who lived in clusters that remained in the registry from 2014 to 2018 . Because of the small number of maternal deaths and the variation in the MMR from year to year, we evaluated the MMR in overlapping periods of 3 years. This approach permitted evaluation using a running average. Because data are not available from the DRC site throughout the entire period of analysis, we report the total MMR with data from the DRC site included and excluded.

The Data Coordinating Center at RTI International (Durham, NC) performed all analyses using SAS, Inc. (Version 9.4). Institutional Review Boards or research ethics committees and Ministries of Health at each site approved the collection of data included in the MNHR. Prior to the initiation of data collection, we used sensitization meetings to gain local approval of study procedures at the community level. Individual participants gave informed consent. The NICHD appointed a data monitoring committee to annually review the MNHR.

\section{Results}

We screened 582,768 women for inclusion in the MNHR from 2010 to 2018. Of those screened, 579,140 (99.4\%) were eligible and consented to be part of the MNHR, (Fig. 1). Of women who consented, 7819 (1.3\%) were lost to follow up, leaving 571,321 (98.6\%) for analysis. These pregnancies resulted in 576,685 outcomes (including multiple gestations): 19,080 (3\%) miscarriages, 14,432 (3\%) stillbirths, 7789 (1\%) MTPs, $225(<0.1 \%)$ unknown birth outcomes and 535,159 (93\%) live births (Table 1). We included data on 842 maternal deaths: 452 (53\%) of the birth outcomes of the women who died were live births, $182(21 \%)$ were stillbirths, $7(<1 \%)$ were miscarriages, $3(<1 \%)$ were MTPs, and 219 (25\%) had unknown birth outcomes. Thus, of the $75 \%$ of cases where fetal or neonatal outcome were known, more than $20 \%$ were associated with stillbirth. We observed an MMR of 157 / 100,000 live births $(95 \%$ CI 147, 167), with a range of MMRs from 


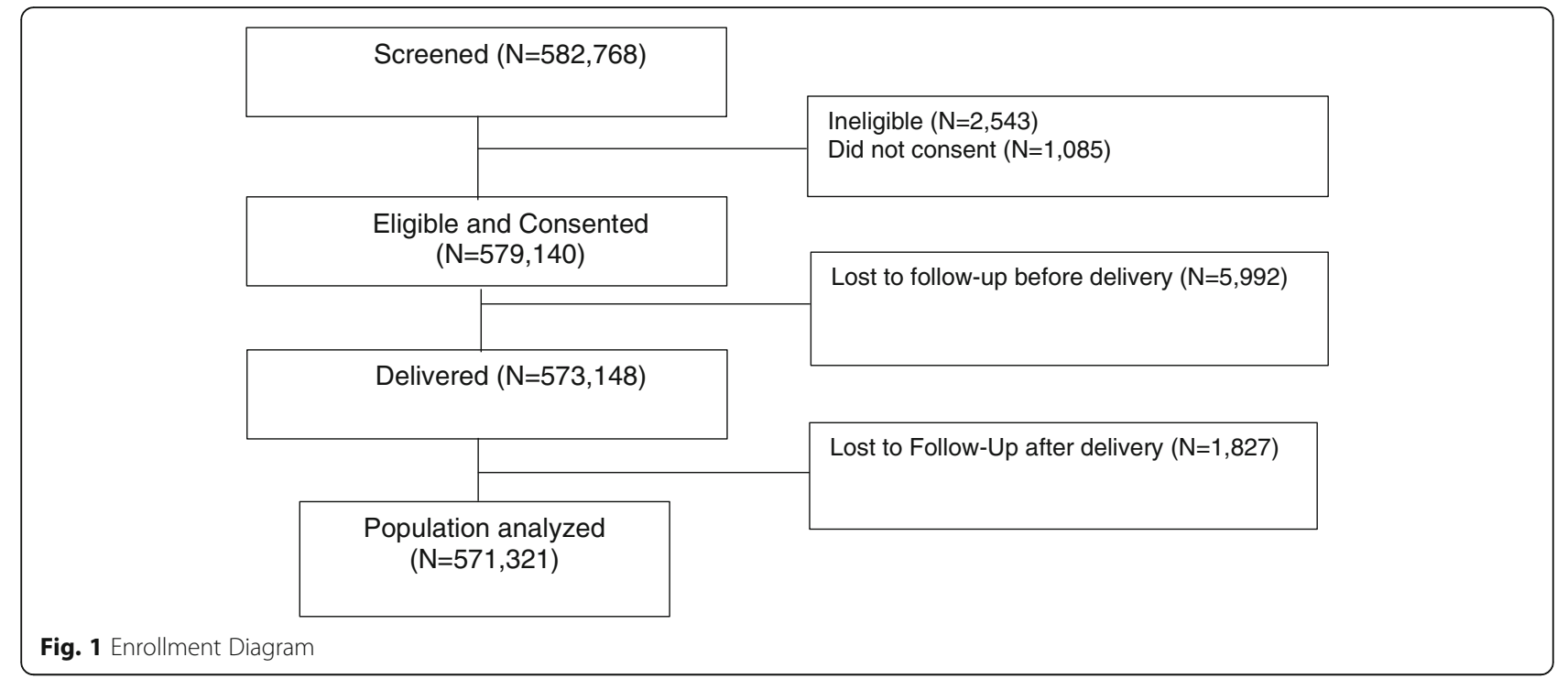

$97(76,118)$ in the Guatemala site to $327(293,361)$ in the Pakistan site.

We evaluated maternal characteristics associated with maternal death (Table 2). Women who were older than 35 years of age, those with no formal or only primary/secondary education compared to university or higher education, nulliparous or multiparous with $>2$ pregnancies, compared to 1-2 prior pregnancies and those whose last pregnancy did not result in a live birth were at an increased risk for maternal death. Antenatal and delivery characteristics that were associated with an increased risk of maternal death included: limited or no ANC, hospital delivery, delivery by a physician, assisted vaginal or Caesarean delivery, obstructed labor, fetal malpresentation, severe antepartum hemorrhage (> $1000 \mathrm{cc}$ blood loss), hypertensive disorders and intrapartum medical treatments such as antibiotics, corticosteroids, blood transfusions, removal of retained products, anticonvulsant medications, IV fluids, use of forceps/vacuum, and other surgeries or treatments (Table 3).

We evaluated selected factors and their association with maternal death using a multivariable model (Table 4). We included site, maternal, antenatal and delivery characteristics in the model to determine the relationship with maternal mortality. After adjusting for differences in characteristics, we found the same direction and similar magnitude of association for age, education and parity. Obstructed labor, severe antepartum hemorrhage, and hypertensive disorders also still had an increased risk of death. However, when adjusted for other factors, malpresentation and

Table 1 Overall pregnancy outcomes by site, 2010-2018, all clusters ${ }^{a}$

\begin{tabular}{|c|c|c|c|c|c|c|c|c|}
\hline Characteristic & $\begin{array}{l}\text { Overall, } \\
\text { all sites }\end{array}$ & $\begin{array}{l}\text { Democratic } \\
\text { Republic of Congo }\end{array}$ & Guatemala & Belagavi & Nagpur & Kenya & Pakistan & Zambia \\
\hline Pregnancies, n & 571,321 & 31,896 & 83,320 & 135,384 & 87,395 & 73,904 & 96,760 & 62,662 \\
\hline Miscarriages, n & 19,080 & 244 & 694 & 8280 & 3322 & 210 & 5877 & 453 \\
\hline $\begin{array}{l}\text { Medical Termination } \\
\text { of Pregnancy, n }\end{array}$ & 7789 & 83 & 1 & 4362 & 1993 & 33 & 1303 & 14 \\
\hline $\begin{array}{l}\text { Unknown birth } \\
\text { outcomes, n }\end{array}$ & 225 & 30 & 10 & 37 & 38 & 23 & 71 & 16 \\
\hline Stillbirths, $n$ & 14,432 & 1239 & 1522 & 3002 & 1775 & 1554 & 4164 & 1176 \\
\hline Live births, $\mathrm{n}$ & 535,159 & 30,870 & 81,672 & 120,629 & 80,917 & 72,973 & 86,458 & 61,640 \\
\hline Maternal deaths, n & 842 & 98 & 79 & 149 & 89 & 78 & 283 & 66 \\
\hline Total MMR(95\% Cl) & $157(147,167)$ & $317(257,378)$ & $97(76,118)$ & $124(106,141)$ & $110(89,131)$ & $107(83,130)$ & $327(293,361)$ & $107(82,132)$ \\
\hline
\end{tabular}

${ }^{a}$ Maternal Newborn Health Registry 2010-2018 deliveries, excluding women lost to follow-up prior to delivery or missing maternal status at 42 days

${ }^{b}$ Maternal Mortality Ratio (MMR) is maternal deaths per 100,000 live births. The $95 \%$ confidence interval for the MMR is approximated using the variance of the proportion of maternal deaths for each site and year 
Table 2 Maternal characteristics by maternal status at 42 days after delivery, 2010-2018 all clusters

\begin{tabular}{|c|c|c|c|c|}
\hline \multirow[t]{2}{*}{ Characteristic $^{\mathrm{a}}$} & \multicolumn{2}{|c|}{$\mathrm{N}(\%)$ by maternal status } & \multirow[t]{2}{*}{ Total } & \multirow[t]{2}{*}{ Risk Ratio $(95 \% \mathrm{Cl})^{\mathrm{b}}$} \\
\hline & Women who died & $\begin{array}{l}\text { Women alive six } \\
\text { weeks after delivery }\end{array}$ & & \\
\hline Deliveries, N & 842 & 570,479 & 571,321 & \\
\hline Maternal age & 839 & 569,478 & 570,317 & \\
\hline$<20$ & $65(7.7)$ & $71,758(12.6)$ & $71,823(12.6)$ & $0.7(0.5,0.9)$ \\
\hline $20-35$ & $695(82.8)$ & $471,940(82.9)$ & $472,635(82.9)$ & 1.0 \\
\hline$>35$ & $79(9.4)$ & $25,780(4.5)$ & $25,859(4.5)$ & $2.0(1.6,2.5)$ \\
\hline Maternal education & 841 & 568,765 & 569,606 & \\
\hline No formal education & $360(42.8)$ & $137,325(24.1)$ & $137,685(24.2)$ & $3.8(2.6,5.6)$ \\
\hline Primary/Secondary & $458(54.5)$ & $391,879(68.9)$ & $392,337(68.9)$ & $1.9(1.3,2.8)$ \\
\hline University + & $23(2.7)$ & $39,561(7.0)$ & $39,584(6.9)$ & 1.0 \\
\hline Parity & 836 & 566,711 & 567,547 & \\
\hline 0 & $238(28.5)$ & $183,868(32.4)$ & $184,106(32.4)$ & $1.2(1.0,1.4)$ \\
\hline $1-2$ & $273(32.7)$ & $240,049(42.4)$ & $240,322(42.3)$ & 1.0 \\
\hline$>2$ & $325(38.9)$ & $142,794(25.2)$ & $143,119(25.2)$ & $1.7(1.5,2.1)$ \\
\hline Last pregnancy did not result in a live birth & $56 / 598(9.4)$ & $21,148 / 382,772(5.5)$ & $21,204 / 383,370(5.5)$ & $1.7(1.3,2.3)$ \\
\hline
\end{tabular}

${ }^{a}$ The denominator used to determine the percentage of women with each characteristic varies due to missing data

${ }^{b}$ Risk ratios were generated from models evaluating the outcome of women who died vs women who were alive six weeks after delivery. Generalized linear models were used to evaluate the relationship of potential factors and maternal mortality and to develop point and interval estimates of relative risk associated with these factors. Generalized estimating equations were used to account for the correlation of outcomes within cluster to develop appropriate confidence intervals. Unless otherwise noted, the reference group is women who did not have the listed characteristic

ANC were no longer associated with risk of death. Of note, delivery location, birth attendance and delivery mode remained significant in the model. However, while physician delivery was still associated with an increased risk of maternal mortality compared to delivery by a nurse/midwife/health worker, it no longer had an increased observed risk compared to traditional birth attendants or family/self/other (RR confidence intervals include 1). Likewise, delivery in a hospital retained a significant association with increased maternal mortality compared to delivery in a clinic/health center, but not compared to home/other. Lastly, while caesarean delivery still showed an association with increased risk of maternal mortality compared to vaginal delivery, vaginal assisted delivery did not.

We identified hemorrhage (33\%), infection (31\%) and pre-eclampsia/eclampsia (16\%) as the most common causes of maternal death overall in our population (Table 5). The primary causes of death varied by site and we observed wide site differences in the percentage of deaths attributable to these causes.

Of the overall study population, we included 466,772 $(81.7 \%)$ for analysis of trends in the MMR over time (Table 6). The total MMR in the ongoing clusters was 158 (147, 169). When we excluded the DRC site from the overall MMR trend, we observed variance in the MMR from $130(112,148)$ to 159 (139, 178). We observed site variation of MMR over time (Fig. 2).
The Zambia site varied in the 3 year running averages from $141(91,192)$ in the earliest interval to $72(36,108)$ in the latest interval. The Kenya site varied from 133 $(90,176)$ in the earliest interval to $103(61,144)$ in the latest interval. The Pakistan site 3 year running averages ranged from $336(265,408)$ to $404(321,488)$. The sites in Guatemala, Belagavi and Nagpur, India had similar MMR from the beginning to the end of the study period. Only 5 years of data were available for the DRC, and the MMR varied little from 289 $(213,365)$ to $294(220,329)$.

\section{Discussion}

Our data show an MMR higher than the SDG 2030 goals in all research sites within the NICHD GN. We measured an MMR of 157 / 100,0000 live births, which is more than double the SDG target of less than 70 per 100,000 live births by 2030. There is great variation in MMR across sites, with the lowest average MMRs during the study period in the Guatemala (97), Kenya (107) and Zambia (107) sites to the highest MMRs measured in the DRC (317) and Pakistan (327) sites. We identified maternal, antenatal and delivery characteristics that were associated with maternal death. We identified hemorrhage, infection and pre-eclampsia/eclampsia as the most common causes of maternal death. Of the $75 \%$ of cases where fetal or neonatal outcome were known, more than 
Table 3 Antenatal and delivery characteristics by maternal status at 42 days after delivery, 2010-2018 all clusters

\begin{tabular}{|c|c|c|c|c|}
\hline \multirow[t]{2}{*}{ Characteristic $^{\mathrm{a}}$} & \multicolumn{2}{|c|}{$\mathrm{N}(\%)$ by maternal status } & \multirow[t]{2}{*}{ Total } & \multirow[t]{2}{*}{ Risk Ratio(95\% Cl) } \\
\hline & Women who died & $\begin{array}{l}\text { Women alive six weeks } \\
\text { after delivery }\end{array}$ & & \\
\hline Deliveries, $\mathrm{N}$ & 842 & 570,479 & 571,321 & \\
\hline No antenatal care (vs. any antenatal care) & $62 / 834(7.4)$ & $20,426 / 570,105(3.6)$ & 20,488/570,939 (3.6) & $1.6(1.1,2.4)$ \\
\hline Fewer than 4 antenatal care visits (vs. $>4$ visits) & $339 / 605(56.0)$ & $201,105 / 447,076(45.0)$ & $201,444 / 447,681(45.0)$ & $1.3(1.1,1.7)$ \\
\hline Birth attendant & 620 & 570,351 & 570,971 & \\
\hline Physician & $291(46.9)$ & $203,294(35.6)$ & $203,585(35.7)$ & 1.0 \\
\hline Nurse/Midwife/Health worker & $131(21.1)$ & 203,325 (35.6) & $203,456(35.6)$ & $0.4(0.3,0.5)$ \\
\hline Traditional birth attendant & $134(21.6)$ & $119,738(21.0)$ & $119,872(21.0)$ & $0.5(0.4,0.7)$ \\
\hline Family/Self/Other & $64(10.3)$ & $43,994(7.7)$ & $44,058(7.7)$ & $0.8(0.6,1.0)$ \\
\hline Delivery location & 623 & 570,402 & 571,025 & \\
\hline Hospital & $335(53.8)$ & $244,926(42.9)$ & $245,261(43.0)$ & 1.0 \\
\hline Clinic/health center & $113(18.1)$ & $170,980(30.0)$ & $171,093(30.0)$ & $0.4(0.3,0.5)$ \\
\hline Home/other & $175(28.1)$ & $154,496(27.1)$ & $154,671(27.1)$ & $0.6(0.5,0.8)$ \\
\hline Delivery mode & 612 & 545,759 & 546,371 & \\
\hline Vaginal & $424(69.3)$ & $466,355(85.5)$ & $466,779(85.4)$ & 1.0 \\
\hline Vaginal assisted & $19(3.1)$ & $5364(1.0)$ & $5383(1.0)$ & $3.3(1.7,6.5)$ \\
\hline Caesarean section & $169(27.6)$ & $74,040(13.6)$ & $74,209(13.6)$ & $2.7(2.3,3.3)$ \\
\hline Obstructed labor & $148 / 697(21.2)$ & $44,947 / 569,869(7.9)$ & 45,095/570,566 (7.9) & $3.0(2.3,3.9)$ \\
\hline Fetal Malpresentation & $45 / 692(6.5)$ & $11,253 / 569,773(2.0)$ & $11,298 / 570,465$ (2.0) & $3.3(2.4,4.4)$ \\
\hline Severe antepartum hemorrhage & $71 / 695(10.2)$ & $8783 / 569,937(1.5)$ & $8854 / 570,632(1.6)$ & $6.7(5.0,9.0)$ \\
\hline Hypertensive disorders & $156 / 688(22.7)$ & $14,650 / 569,679(2.6)$ & $14,806 / 570,367(2.6)$ & $10.6(8.5,13.2)$ \\
\hline \multicolumn{5}{|l|}{ Maternal treatment provided } \\
\hline Maternal antibiotics & $350 / 559(62.6)$ & 229,932/464,473 (49.5) & 230,282/465,032 (49.5) & $2.3(1.8,2.9)$ \\
\hline Corticosteroids & 43/439 (9.8) & $10,225 / 413,905(2.5)$ & $10,268 / 414,344(2.5)$ & $4.0(2.8,5.9)$ \\
\hline Oxytocics (including Misoprostol) & $344 / 556(61.9)$ & $308,315 / 463,555(66.5)$ & $308,659 / 464,111(66.5)$ & $0.9(0.7,1.1)$ \\
\hline Blood transfusion & 186/560 (33.2) & $9789 / 464,309(2.1)$ & $9975 / 464,869(2.1)$ & $20.9(16.0,27.2)$ \\
\hline Removal of retained products & $45 / 558(8.1)$ & $20,750 / 464,252(4.5)$ & $20,795 / 464,810(4.5)$ & $2.1(1.4,3.1)$ \\
\hline Anticonvulsants/Magnesium sulfate & 60/553 (10.8) & $5692 / 464,277(1.2)$ & $5752 / 464,830(1.2)$ & $9.8(7.2,13.4)$ \\
\hline V Fluids & 182/258 (70.5) & $90,672 / 173,017(52.4)$ & $90,854 / 173,275(52.4)$ & $2.4(1.7,3.4)$ \\
\hline Forceps/vacuum & $13 / 254(5.1)$ & 1908/172,354 (1.1) & 1921/172,608 (1.1) & $4.3(2.4,7.7)$ \\
\hline Other surgery/treatment & 22/255 (8.6) & $9830 / 172,810(5.7)$ & $9852 / 173,065(5.7)$ & $1.7(1.1,2.7)$ \\
\hline
\end{tabular}

a The denominator used to determine the percentage of women with each characteristic varies due to missing data

${ }^{b}$ Risk ratios were generated from models evaluating the outcome of women who died vs women who were alive six weeks after delivery. Generalized linear models were used to evaluate the relationship of potential factors and maternal mortality and to develop point and interval estimates of relative risk associated with these factors. Generalized estimating equations were used to account for the correlation of outcomes within cluster to develop appropriate confidence intervals. Unless otherwise noted, the reference group is women who did not have the listed characteristic

$20 \%$ were associated with stillbirth. We observed some sites with improvement in the MMR over time, but the Pakistani site reported an increase in the MMR over time.

When compared to the World Bank modeled estimates for the MMR by country, our data indicate a lower MMR for the sites in all countries, except Pakistan [17]. For example, we measured an MMR of 317 in the DRC site, compared to the World
Bank estimates of 850, and we measured an MMR of 107 in the Zambia site, compared to the World Bank estimate of 398 [7]. The World Bank estimates are developed from representative samples of the populations across countries in contrast to our MMR which measures outcomes in a region within the country. Our data are collected at the individual level within a discrete population within each country. It might not be representative of the entire 
Table 4 Multivariable model of maternal status at 42 days after delivery controlling for site, maternal, antenatal and delivery characteristics, 2010-2018 all clusters

\begin{tabular}{|c|c|c|}
\hline Characteristic & Overall $p$-value ${ }^{a}$ & $\begin{array}{l}\text { Risk Ratio } \\
(95 \% \mathrm{Cl})^{\mathrm{a}}\end{array}$ \\
\hline Maternal age & 0.0017 & \\
\hline$<20$ & & $0.64(0.45,0.89)$ \\
\hline $20-35$ & & 1.0 \\
\hline$>35$ & & $1.43(1.06,1.92)$ \\
\hline Maternal education & $<.0001$ & \\
\hline No formal education & & $3.40(2.08,5.55)$ \\
\hline Primary/Secondary & & $2.46(1.54,3.94)$ \\
\hline University + & & 1.0 \\
\hline Parity & 0.0031 & \\
\hline 0 & & $1.24(1.01,1.52)$ \\
\hline $1-2$ & & 1.0 \\
\hline$>2$ & & $1.48(1.15,1.89)$ \\
\hline At least one antenatal care visit & 0.1707 & $1.22(0.92,1.61)$ \\
\hline Birth attendant & $<.0001$ & \\
\hline Physician & & 1.0 \\
\hline Nurse/Midwife/Health worker & & $0.61(0.45,0.84)$ \\
\hline Traditional birth attendant & & $0.74(0.50,1.10)$ \\
\hline Family/Self/Other & & $1.38(0.91,2.09)$ \\
\hline Delivery location & $<.0001$ & \\
\hline Hospital & & 1.0 \\
\hline Clinic/health center & & $0.57(0.44,0.75)$ \\
\hline Home/other & & $0.89(0.62,1.28)$ \\
\hline Delivery mode & 0.0048 & \\
\hline Vaginal & & 1.0 \\
\hline Vaginal assisted & & $1.58(0.80,3.12)$ \\
\hline Caesarean section & & $1.60(1.21,2.13)$ \\
\hline Obstructed labor & 0.0062 & $1.58(1.14,2.19)$ \\
\hline Fetal Malpresentation & 0.1140 & $1.30(0.94,1.79)$ \\
\hline Severe antepartum hemorrhage & $<.0001$ & $2.59(1.83,3.66)$ \\
\hline Hypertensive disorders & $<.0001$ & $6.87(5.05,9.34)$ \\
\hline
\end{tabular}

${ }^{a}$ A generalized linear model was used to evaluate the relationship of potential factors and maternal mortality and to develop point and interval estimates of relative risk associated with these factors after controlling for site and all other listed characteristics. Generalized estimating equations were used to account for the correlation of outcomes within cluster to develop appropriate confidence intervals. Unless otherwise noted, the reference group is women who did not have the listed characteristic

population of the diverse countries in which we work. For example, our data from the rural provinces in the DRC are likely not reflective of the population in the urban capital of Kinshasa. However, we do not believe that this variation in methodology entirely accounts for the wide discrepancies we have observed. We presume these data highlight the differences between data measured prospectively in a direct fashion, compared to indirect measurements and estimates derived from modelling strategies with unknown reliability.

We describe an increased risk of maternal death among women who deliver in hospitals, those who have deliveries attended by physicians and those who deliver by Caesarean section. We presume that the women who seek care by a physician or in a hospital are at higher risk for pregnancy complications or have experienced pregnancy complications that have required a higher level of medical care. Therefore, we believe that these associations are confounded by indication. This presumption is consistent with previous literature that indicates that the largest proportion of maternal deaths occur in facilities where the higher risk patients are treated and where complicated patients are referred [18]. Ronsmans and colleagues describe three categories of women who die in hospitals: women who arrive in a moribund state too late to benefit from emergency medical treatment, high risk women who could have been saved if they received timely and effective interventions and women who develop serious complications within the hospital [18]. While our data are consistent with findings that hospital delivery is associated with higher maternal mortality, we do not have data on the quality of care that was delivered to these women or at what point in the mother's illness she arrived at the hospital for care.

The MNHR represents a useful tool for recording and tracking the MMR in several LMICs. Our data are rigorously collected in a prospective fashion with consistent methodology over a long period of time. Because we collect data from all pregnant women living in a geographic area, regardless of delivery site, the MNHR is ideal for giving an accurate account of the MMR in the population studied. The MNHR has a high rate of recruitment and retention (outcomes obtained on $98.6 \%$ of women) which provides robust data for studying maternal and neonatal outcomes through 6 post-partum weeks, referenced elsewhere in the supplement. Furthermore, the MNHR contains data from a consistent population of women in LMICs over a 9-year period. This ongoing data collection tool is ideal for examining trends in health outcomes within study regions over time.

The MNHR does have some practical limitations. Women can be enrolled in the MNHR at any point in their pregnancy, so we potentially underrepresent maternal death that occurs early in pregnancy that could be related to miscarriages or MTPs. Our analyses are also limited to the variables that are collected within the 
Table $\mathbf{5}$ Cause of maternal death by site, all clusters

\begin{tabular}{|c|c|c|c|c|c|c|c|c|}
\hline Characteristic & Overall & DRC & Guatemala & Belagavi & Nagpur & Kenya & Pakistan & Zambia \\
\hline Maternal deaths ${ }^{a}, \mathrm{n}$ & 842 & 98 & 79 & 149 & 89 & 78 & 283 & 66 \\
\hline Maternal cause of death data available ${ }^{\mathrm{b}}, \mathrm{n}(\%)$ & $436(51.8)$ & $97(99.0)$ & $46(58.2)$ & $50(33.6)$ & $43(48.3)$ & $35(44.9)$ & $139(49.1)$ & $26(39.4)$ \\
\hline Maternal cause of death, $\mathrm{n}(\%)$ & 436 & 97 & 46 & 50 & 43 & 35 & 139 & 26 \\
\hline Trauma & $22(5.0)$ & $4(4.1)$ & $2(4.3)$ & $4(8.0)$ & $2(4.7)$ & $5(14.3)$ & $3(2.2)$ & $2(7.7)$ \\
\hline Abortion related & $21(4.8)$ & $6(6.2)$ & $1(2.2)$ & $1(2.0)$ & $2(4.7)$ & $6(17.1)$ & $4(2.9)$ & $1(3.8)$ \\
\hline Preeclampsia/ Eclampsia & $69(15.8)$ & $10(10.3)$ & $16(34.8)$ & $8(16.0)$ & $5(11.6)$ & $10(28.6)$ & $15(10.8)$ & $5(19.2)$ \\
\hline Hemorrhage & $144(33.0)$ & $41(42.3)$ & $14(30.4)$ & $16(32.0)$ & $13(30.2)$ & $8(22.9)$ & $44(31.7)$ & $8(30.8)$ \\
\hline Infection & $136(31.2)$ & 18 (18.6) & $13(28.3)$ & $20(40.0)$ & $13(30.2)$ & $2(5.7)$ & $63(45.3)$ & $7(26.9)$ \\
\hline Medical condition coincident to pregnancy & $23(5.3)$ & $9(9.3)$ & $0(0.0)$ & $1(2.0)$ & $4(9.3)$ & $1(2.9)$ & $6(4.3)$ & $2(7.7)$ \\
\hline Unknown & $21(4.8)$ & $9(9.3)$ & $0(0.0)$ & $0(0.0)$ & $4(9.3)$ & $3(8.6)$ & $4(2.9)$ & $1(3.8)$ \\
\hline
\end{tabular}

a Maternal Newborn Health Registry (MNHR) 2010-2018 deliveries, excluding women lost to follow up prior to delivery or missing maternal status at 42 days

${ }^{b}$ Maternal cause of death data collected from late 2013 to 2018. Cause of death determined by a standardized, heirarchical algorithm [16] in which one cause of death is identified, therefore, categories are mutually exclusive

MNHR. For example, the causes of maternal death are estimates using interview techniques and medical chart extraction. Supportive laboratory data were rarely available and autopsies were not performed. As such, these data were not included in the cause of death algorithm [16]. Additionally, sites that do not routinely measure blood pressures as part of ANC, report lower rates of pre-eclampsia/eclampsia. However, despite these biases, our approach to identify causes of death found similar relative contributions to other published reports. Therefore, our approach might represent an opportunity to identify maternal health practices that could prevent specific causes of mortality $[19,20]$.

\section{Conclusions}

The results of our study contribute important MMR data in 6 LMICs. The differences that we described, compared to MMRs from modelling estimates, illustrate the vast variation in MMR estimates given the data source and strategy used. Because our data are collected prospectively, we believe that the MNHR is an ideal source for evaluating key health outcomes. The high, but relatively stable, MMR in many countries highlights an opportunity for improvement in these countries. While the Guatemalan and Zambian sites have demonstrated success in lowering the MMR over the study period, sites in other countries,

Table 6 Trend in maternal mortality ratio by site and combined years, 2010-2018 in ongoing clusters ${ }^{\mathrm{a}}$

\begin{tabular}{|c|c|c|c|c|c|c|c|c|c|}
\hline Characteristic & Overall, all sites & $\begin{array}{l}\text { Overall, } \\
\text { excluding DRC }\end{array}$ & DRC & Guatemala & Belagavi & Nagpur & Kenya & Pakistan & Zambia \\
\hline \multicolumn{10}{|l|}{ Ongoing clusters ${ }^{a}$} \\
\hline Births, $n$ & 466,772 & 434,876 & 31,896 & 60,434 & 88,684 & 84,241 & 73,904 & 64,951 & 62,662 \\
\hline Maternal deaths, $\mathrm{n}$ & 694 & 596 & 98 & 69 & 95 & 84 & 78 & 204 & 66 \\
\hline Deliveries, $\mathrm{n}$ & 471,272 & 438,806 & 32,466 & 60,832 & 89,300 & 84,872 & 74,793 & 65,710 & 63,299 \\
\hline Live births, $\mathrm{n}$ & 438,855 & 407,985 & 30,870 & 59,198 & 78,265 & 77,968 & 72,973 & 57,941 & 61,640 \\
\hline Total MMR(95\% Cl $)^{\mathrm{a}}$ & $158(147,169)$ & $146(135,157)$ & $317(257,378)$ & $117(90,143)$ & $121(100,143)$ & $108(86,129)$ & $107(83,130)$ & $352(309,395)$ & $107(82,132)$ \\
\hline \multicolumn{10}{|c|}{ MMR, maternal deaths per 100,000 live births $(95 \% \mathrm{CI}))^{\mathrm{b}}$} \\
\hline 2010-2012 & $159(139,178)$ & $159(139,178)$ & & $120(68,172)$ & $135(100,170)$ & $110(74,146)$ & $133(90,176)$ & $336(265,408)$ & $141(91,192)$ \\
\hline 2011-2013 & $151(132,169)$ & $151(132,169)$ & & $110(63,158)$ & $124(91,158)$ & $99(64,134)$ & $114(74,154)$ & $374(299,450)$ & $124(76,172)$ \\
\hline $2012-2014$ & $139(121,158)$ & $139(121,158)$ & & $119(71,168)$ & $106(73,139)$ & $108(71,144)$ & $101(62,141)$ & $326(255,397)$ & $116(69,163)$ \\
\hline 2013-2015 & $130(112,148)$ & $130(112,148)$ & & $106(63,150)$ & $92(59,125)$ & $106(70,142)$ & $81(45,117)$ & $323(253,393)$ & $108(63,153)$ \\
\hline 2014-2016 & $149(131,168)$ & $130(112,148)$ & $289(213,365)$ & $114(70,158)$ & $82(48,115)$ & $117(79,155)$ & $92(53,131)$ & $326(255,397)$ & $77(40,114)$ \\
\hline $2015-2017$ & $162(143,181)$ & $143(124,162)$ & $289(215,364)$ & $130(84,176)$ & $109(70,148)$ & $97(62,132)$ & $98(58,138)$ & $386(307,465)$ & $89(50,129)$ \\
\hline $2016-2018$ & $168(148,188)$ & $149(129,169)$ & $294(220,369)$ & $124(79,169)$ & $136(91,181)$ & $107(69,145)$ & $103(61,144)$ & $404(321,488)$ & $72(36,108)$ \\
\hline
\end{tabular}

${ }^{a}$ Maternal Newborn Health Registry 2010-2018 deliveries, excluding women lost to follow-up prior to delivery or missing maternal status at 42 days. Clusters collecting data during the enti re period of 2010-2018, or 2014-2018 for DRC

${ }^{b}$ Maternal Mortality Ratio (MMR) is maternal deaths per 100,000 live births. The $95 \%$ confidence interval for the MMR is approximated using the variance of the proportion of maternal deaths for each site and year 


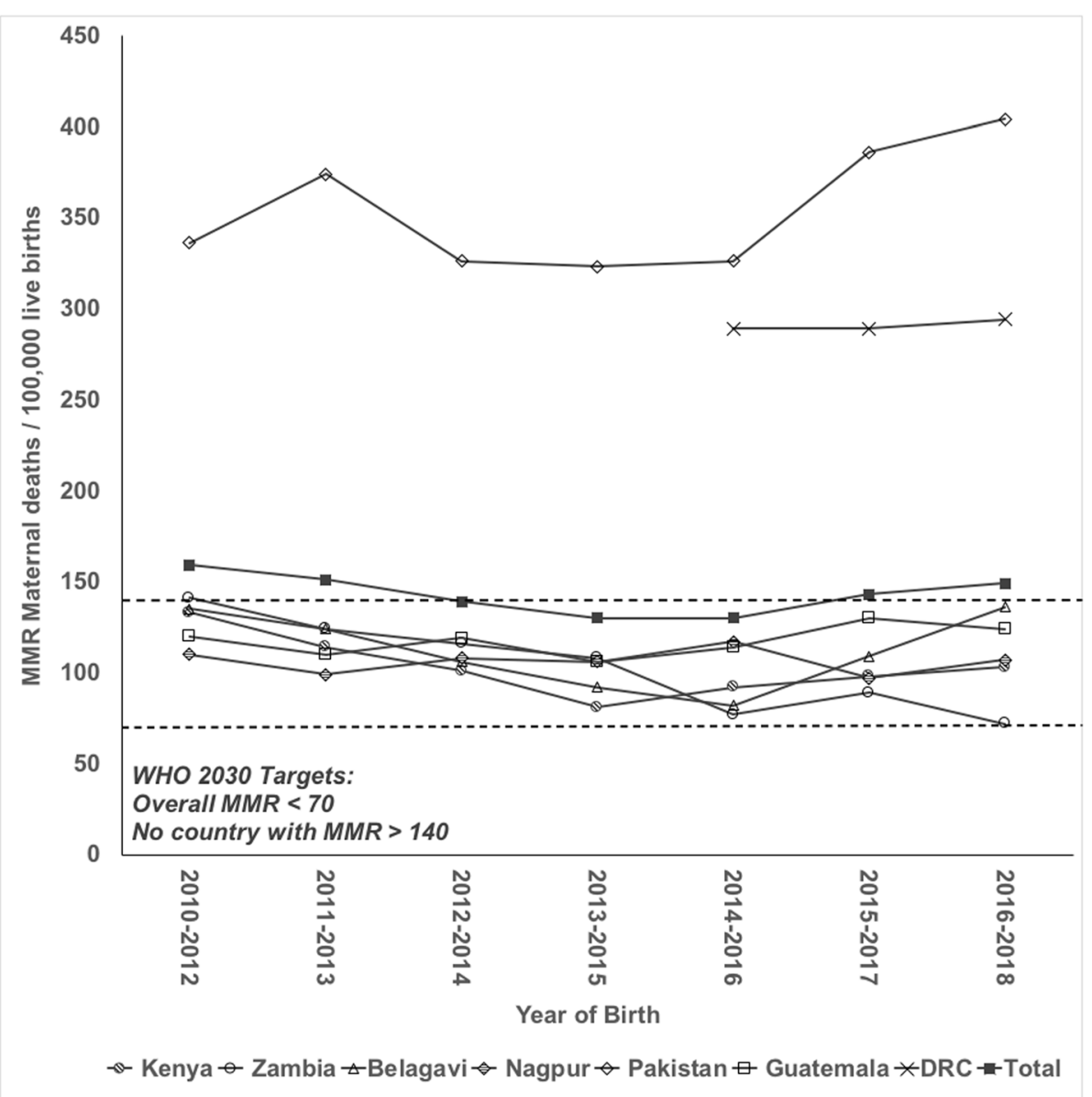

Fig. 2 Running average of maternal mortality ratio ${ }^{1}$ by site and years, 2010-2018 ongoing clusters ${ }^{2} .{ }^{1}$ Maternal Mortality Ratio (MMR) is maternal deaths per 100,000 live births. ${ }^{2}$ Maternal Newborn Health Registry 2010-2018 deliveries excluding women lost to follow-up prior to delivery or missing maternal status at 42 days. Clusters collecting data during the entire period of 2010-2018, or in the DRC where clusters collecting data from 2014 to 2018 are represented. DRC is excluded from total, since data not known prior to 2014

like the DRC and Pakistan, had persistently high MMRs at the end of the study period. Maternal mortality is an important public health problem and these data confirm the opportunity for improvement.

\section{Abbreviations}

SDG: Sustainable Development Goals; MMR: Maternal Mortality Ratio; LMIC: Low and lower-middle income countries; NICHD: National Institute of Health Eunice Kennedy Shriver National Institute of Child Health and Human Development; GN: NICHD Global Network for Women's and Children's Health Research; MNHR: Maternal Newborn Health Registry; DRC: Democratic Republic of Congo; MTP: Medical Termination of Pregnancy; ANC: Antenatal care; RR: Relative Risk; Cl: Confidence Intervals

\section{Acknowledgements}

Not applicable.

\section{About this supplement}

This article has been published as part of Reproductive Health, Volume 17 Supplement 3, 2020: Global Network MNH. The full contents of the supplement are available at https://reproductive-health-journal. biomedcentral.com/articles/supplements/volume-17-supplement-3.

\section{Authors' contributions}

$M B, V T$, TN, $E M, R G$ and $C B$ conceived of the idea for this paper. AL, AT, AP, $P H, A G, N K, F E, P N, E L, W C, E C, S G, R D, S S, R G$, and EM carried out the research. VT, TN, and EM performed the analyses. MB prepared the first draft of the manuscript. JP, MB, RH, MK, WP and all authors reviewed and edited subsequent manuscript drafts. All authors reviewed and approved the final manuscript.

\section{Funding}

Publication of this supplement is funded by grants from Eunice Kennedy Shriver National Institute of Child Health and Human Development. The funders had no input in the design of the study, collection, analysis, interpretation of data or in the writing of the manuscript, with the exception of the Program Officer of NICHD, whose contributions are outlined.

\section{Availability of data and materials}

The datasets generated and analysed during the current study are not yet publicly available due to ongoing data analyses, but they will be available in the NICHD Data and Specimen Hub. Requests for data prior to the public release will be handled by the authors.

Ethics approval and consent to participate

At each site, institutional review boards or ethics committess approved the study. All women provided written informed consent before the start. 


\section{Consent for publication}

Not applicable.

\section{Competing interests}

The authors declare that they have no competing interests.

\section{Author details}

'Department of Pediatrics, University of North Carolina School of Medicine, 101 Manning Drive, CB 7596, Chapel Hill, NC 27599-7596, USA. ${ }^{2}$ RTI International, Durham, NC, USA. 'Kinshasa School of Public Health, Kinshasa, Democratic Republic of Congo. ${ }^{4}$ Lata Medical Research Foundation, Nagpur, India. ${ }^{5}$ Adjunct Faculty Medical Research, Datta Meghe Institute of Medical Sciences, Sawangi, India. ${ }^{6}$ Boston University School of Public Health, Boston, MA, USA. Instituto de Nutrición de Centroamérica y Panamá, Guatemala City, Guatemala. ${ }^{8}$ University of Colorado School of Medicine, Denver, CO, USA. ${ }^{9}$ Moi University School of Medicine, Eldoret, Kenya. ${ }^{10}$ Indiana School of Medicine, University of Indiana, Indianapolis, IN, USA. ${ }^{11}$ University of Alabama at Birmingham, Birmingham, AL, USA. ${ }^{12}$ University Teaching Hospital, Lusaka, Zambia. ${ }^{13} \mathrm{KLE}$ Academy Higher Education and Research, J N Medical College Belagavi, Belgaum, Karnataka, India. ${ }^{14}$ Thomas Jefferson University, Philadelphia, USA. ${ }^{15}$ Aga Khan University, Karachi, Pakistan. ${ }^{16}$ Maternal and Child Health Division (icddr, b), Dhaka, Bangladesh. ${ }^{17}$ Sydney School of Public Health, The University of Sydney, Sydney, NSW 2006, Australia. ${ }^{18}$ Eunice Kennedy Shriver National Institute of Child Health and Human Development, Bethesda, MD, USA. ${ }^{19}$ Department of Obstetrics and Gynecology, Columbia University School of Medicine, New York, NY, USA.

Received: 28 August 2020 Accepted: 2 September 2020 Published: 17 December 2020

\section{References}

1. SDG 3: Ensure healthy lives and promote wellbeing for all at all ages [https://www.who.int/sdg/targets/en/] Accessed 14 Jan 2020.

2. McArthur JW, Rasmussen K, Yamey G. How many lives are at stake? Assessing 2030 sustainable development goal trajectories for maternal and child health. BMJ. 2018;360:k373.

3. Zureick-Brown S, Newby H, Chou D, Mizoguchi N, Say L, Suzuki E, Wilmoth J. Understanding global trends in maternal mortality. Int Perspect Sex Reprod Health. 2013;39:32-41.

4. Sajedinejad S, Majdzadeh R, Vedadhir A, Tabatabaei MG, Mohammad K. Maternal mortality: a cross-sectional study in global health. Glob Health. 2015;11:4.

5. Girum T, Wasie A. Correlates of maternal mortality in developing countries: an ecological study in 82 countries. Matern Health Neonatol Perinatol. 2017:3:19.

6. Ozimek JA, Kilpatrick SJ. Maternal mortality in the twenty-first century Obstet Gynecol Clin N Am. 2018;45:175-86.

7. Maternal Mortality Ratio [ https://data.worldbank.org/indicator/SH.STA. MMRT?view=chart], Accessed 6 Dec 2019.

8. Alkema L, Chou D, Hogan D, Zhang S, Moller AB, Gemmill A, Fat DM, Boerma T, Temmerman M, Mathers C, et al. Global, regional, and national levels and trends in maternal mortality between 1990 and 2015, with scenario-based projections to 2030: a systematic analysis by the UN maternal mortality estimation inter-agency group. Lancet. 2016;387:462-74.

9. St Pierre A, Zaharatos J, Goodman D, Callaghan WM. Challenges and opportunities in identifying, reviewing, and preventing maternal deaths. Obstet Gynecol. 2018;131:138-42.

10. Wilmoth JR, Mizoguchi N, Oestergaard MZ, Say L, Mathers CD, ZureickBrown S, Inoue M, Chou D. A new method for deriving global estimates of maternal mortality. Stat Politics Policy. 2012;3:2151-7509.1038.

11. Collaborators GBDCM. Global, regional, national, and selected subnational levels of stillbirths, neonatal, infant, and under-5 mortality, 1980-2015: a systematic analysis for the global burden of disease study 2015. Lancet. 2016:388:1725-74.

12. Dorrington RE, Bradshaw D. Acknowledging uncertainty about maternal mortality estimates. Bull World Health Organ. 2016;94:155-6.

13. Mgawadere F, Kana T, van den Broek N. Measuring maternal mortality: a systematic review of methods used to obtain estimates of the maternal mortality ratio (MMR) in low- and middle-income countries. Br Med Bull. 2017;121:121-34.
14. Bose CL, Bauserman M, Goldenberg RL, Goudar SS, McClure EM, Pasha O, Carlo WA, Garces A, Moore JL, Miodovnik M, Koso-Thomas M. The global network maternal newborn health registry: a multi-national, communitybased registry of pregnancy outcomes. Reprod Health. 2015;12(Suppl 2):S1.

15. Bauserman M, Lokangaka A, Thorsten V, Tshefu A, Goudar SS, Esamai F, Garces A, Saleem S, Pasha O, Patel A, et al. Risk factors for maternal death and trends in maternal mortality in low- and middle-income countries: a prospective longitudinal cohort analysis. Reprod Health. 2015;12(Suppl 2):S5.

16. Pasha O, McClure EM, Saleem S, Tikmani SS, Lokangaka A, Tshefu A, Bose $\mathrm{CL}$, Bauserman M, Mwenechanya M, Chomba E, et al. A prospective cause of death classification system for maternal deaths in low and middleincome countries: results from the global network maternal newborn health registry. BJOG. 2018;125:1137-43.

17. Pasha O, Saleem S, Ali S, Goudar SS, Garces A, Esamai F, Patel A, Chomba E, Althabe F, Moore $J$, et al. Maternal and newborn outcomes in Pakistan compared to other low and middle income countries in the global Network's maternal newborn health registry: an active, community-based, pregnancy surveillance mechanism. Reprod Health. 2015;12(Suppl 2):S15.

18. Ronsmans C, Graham WJ, steering g LMSS. Maternal mortality: who, when, where, and why. Lancet. 2006;368:1189-200.

19. Black RE, Laxminarayan R, Temmerman M, et al editors. Washington (DC): The International Bank for Reconstruction and Development / The World Bank; 2016

20. Collaborators GBDMM. Global, regional, and national levels of maternal mortality, 1990-2015: a systematic analysis for the global burden of disease study 2015. Lancet. 2016;388:1775-812.

\section{Publisher's Note}

Springer Nature remains neutral with regard to jurisdictional claims in published maps and institutional affiliations.

Ready to submit your research? Choose BMC and benefit from:

- fast, convenient online submission

- thorough peer review by experienced researchers in your field

- rapid publication on acceptance

- support for research data, including large and complex data types

- gold Open Access which fosters wider collaboration and increased citations

- maximum visibility for your research: over $100 \mathrm{M}$ website views per year

At $\mathrm{BMC}$, research is always in progress.

Learn more biomedcentral.com/submission 